Characteristics and outcome of patients with the ICU Admission diagnosis of status epilepticus in Australia and New Zealand

\author{
Hay, Alison
}

2016

Hay , A , Bellomo , R , Pilcher , D , Jackson , G, Kaukonen , K-M \& Bailey , M 2016 , '

Characteristics and outcome of patients with the ICU Admission diagnosis of status

epilepticus in Australia and New Zealand ', Journal of Critical Care , vol. 34 , pp. 146-153 . https://doi.org/10.1016/j.J

http://hdl.handle.net/10138/224066

https://doi.org/10.1016/j.jcrc.2016.03.003

publishedVersion

Downloaded from Helda, University of Helsinki institutional repository.

This is an electronic reprint of the original article.

This reprint may differ from the original in pagination and typographic detail.

Please cite the original version. 
Outcomes/Predictions

\title{
Characteristics and outcome of patients with the ICU Admission diagnosis of status epilepticus in Australia and New Zealand
}

\author{
Alison Hay ${ }^{\mathrm{a}}$, Rinaldo Bellomo a,b,c,*, David Pilcher ${ }^{\mathrm{a}, \mathrm{c}, \mathrm{d}}$, Graeme Jackson ${ }^{\mathrm{e}}$, \\ Kirsi-Majia Kaukonen ${ }^{c, f}$, Michael Bailey ${ }^{c}$ \\ a Austin Hospital, Heidelberg, Melbourne, Victoria, Australia \\ b The University of Melbourne, Parkville, Victoria, Australia \\ c The Australian and New Zealand Intensive Care Research Centre, Monash University School of Publish Health and Preventive Medicine, Melbourne, Australia \\ d Australian and New Zealand Intensive Care Society Centre for Outcome Research and Evaluation, Melbourne, Australia \\ e Brain Research Institute, Melbourne, Victoria, Australia \\ ${ }^{\mathrm{f}}$ Department of Anaesthesiology and Intensive Care, Helsinki University, Helsinki, Finland
}

\section{A R T I C L E I N F O}

\section{Keywords:}

intensive care unit (ICU)

seizures

epilepsy

epidemiology

ventilation

mortality

\begin{abstract}
A B S T R A C T
Objectives: Status epilepticus (SE) is a neurological emergency and may lead to Intensive Care Unit (ICU) admission. However, little is known about the characteristics and outcome of patients with the ICU admission diagnosis of SE.

Methods: We performed a retrospective study of patients admitted to ICU with the primary admission diagnosis of SE as recorded in the Australian and New Zealand Intensive Care Society (ANZICS) Adult Patient Database over more than a decade. We examined the ICU and population incidence, physiological and demographic features of such SE patients; compared ventilated and non-ventilated SE patients and assessed their mortality.

Results: From 2000-2013, 12,926 patients (1.2\% of all ICU admissions) were admitted to ANZ ICUs with SE as the main admission diagnosis. Over the study period, the ICU prevalence ( 0.93 vs $1.13 \%$ ), population incidence ( 30 vs 61 per million population), ICU length of stay (1.45 vs 1.77 days) and the rate of discharge to a rehabilitation facility ( 2.3 vs $7.1 \%$ ) of SE increased $(\mathrm{P}<.0001)$. In contrast, the use of mechanical ventilation $(56.6 \mathrm{vs} 47.2 \%)$, hospital length of stay ( 6.64 vs 5.81 days), ICU ( 2.6 vs $0.75 \%$ ) and hospital ( 8.2 vs $4 \%$ ) mortality decreased (P<.0001). Overall hospital mortality was 613 (4.7\%) with 219 (1.7\%) patients dying in ICU. Mortality was associated with advancing age, multiple co-morbidities, lower GCS on admission and higher APACHE III scores. From 2000 to 2013 ICU mortality decreased from $2.6 \%$ to $0.75 \%$.

Significance: Over a 14-year period in ANZ, there have been major changes in the features, management and outcome of patients admitted to ICU with the primary admission diagnosis of SE such that their ICU mortality is now $<1 \%$.
\end{abstract}

(C) 2016 Elsevier Inc. All rights reserved.

\section{Introduction}

Status epilepticus (SE) is a neurological emergency [1-8]. SE exposes patients to significant morbidity [2-4,9] including cognitive impairment, neurological deficits and mortality [2,4]. When refractory, SE typically requires Intensive Care Unit (ICU) admission [10] and often endotracheal intubation, mechanical ventilation, deep sedation and even barbiturate induced coma [2]. SE patients who receive mechanical ventilation have been reported to have significantly increased mortality [1], may need prolonged ventilation [5], and often experience extended length ICU [2,3] and hospital stay [1]. Finally, the mortality of patients

\footnotetext{
* Corresponding author at: The University of Melbourne, Department of Intensive Care, Austin Hospital, Studley Rd, Heidelberg, Victoria, 3084, Australia. Tel.: +61 3 94965992; fax: + 61394963932 .

E-mail address: rinaldo.bellomo@austin.org.au (R. Bellomo).
}

admitted to hospital with SE has previously been reported to vary from $3.45 \%$ to $67 \%[1,10]$ depending on the selection criteria [11].

In a consensus statement [11] it was recently asserted that mortality for SE is $20 \%$, with $30 \%$ of patients having SE not controlled by initial treatment and with no cause identified in $30 \%$. However, all of these studies have reported data on patients with a variable combination of SE on admission and SE that develops within the ICU or the hospital in patients with a different initial admission diagnosis; have often studied SE as a secondary event caused by other major primary admission diagnosis (e.g. traumatic brain injury, brain tumors, stroke) and have assessed patients irrespective of ICU admission and/or mechanical ventilation. Thus, no information exists on the epidemiology of patients with SE as the primary reason for admission to ICU [11,12].

Accordingly, we interrogated the Australian and New Zealand (ANZ) bi-national Intensive Care Registry [13] and obtained information on the incidence, characteristics, and outcome of patients admitted to ANZ ICUs with the primary ICU admission diagnosis of $\mathrm{SE}$, over the last 14 years. 


\section{Methods}

We conducted a retrospective study using data from the Australian and New Zealand Intensive Care Society (ANZICS) Adult Patient Database (APD) [13] run by the Centre for Outcome and Resource Evaluation. The ANZICS APD is set up as a clinical registry, using clinically relevant diagnoses for Critical Care clinicians. Diagnostic coding is primarily done by trained data collectors and clinicians. In 2014 there were 200 ICUs in ANZ. All tertiary ICUs with one exception submitted data to the APD and national coverage approximated $90 \%$ of all ICU and $99 \%$ of all ICUs able to admit and manage SE patients without the need for transfer to a referral hospital. Those that did not submit were predominantly smaller regional/rural units and small private units, which transfer SE patients to major regional or tertiary ICUs. ICUs are defined by the ANZ College of Intensive Care Medicine criteria. The principle of APD contribution is that any organization may submit data on their ICU if it is a geographical area equipped for the monitoring and treatment of critically ill patients, and patients are under the care of critical care team and have a dedicated college trained ICU director.

The study was approved by the Alfred Hospital Human Research Ethics Committee, Melbourne, Australia with a waiver of informed consent. Population data were retrieved from the Australian Bureau of Statistics [14] and Statistics New Zealand [15].

\subsection{Description of patients}

We included all adult patients with the primary admission diagnosis of Status Epilepticus (SE). We assumed the widely accepted diagnosis of SE as seizures persisting for greater than 30 minutes. This means that, according to the data dictionary instructions for the APD classification of such patients, even though some patients may have had sepsis, underlying known epilepsy, electrolyte disorders, or other medical conditions predisposing to SE, the primary and dominant reason for admission to ICU was the need to manage SE. Thus most patients likely had refractory SE and had not responded to initial treatment. We excluded patients younger than 16 years of age, readmissions, those with missing mortality data and those who had SE secondary to new underlying brain pathology which had also been diagnosed on that same admission (brain tumor, stroke, traumatic brain injury). Furthermore, we excluded patients who had a cardiac arrest prior to admission to ICU and those admitted to ICU from the operating theater (OT). This is because, according to the APD data dictionary, anyone admitted from OT is always given an operative diagnosis as the only one diagnosis entered into the registry. Thus 'SE' in this study does not include patients who developed SE as an anesthetic complication in OT or another hospital or ICU. (Transfers were excluded to avoid counting patient outcomes twice since they would appear as an ICU admission in the data from both hospitals). We analyzed all hospital outcomes (mortality, discharge home, discharge to another hospital and discharge to a rehabilitation facility). Finally, we assessed both the ICU and hospital length of stay.

\subsection{Statistical analysis}

Data are presented as percentages (number), means (standard deviation, SD), medians (interquartile range, IQR) or proportion (95\% confidence interval, CI). Accordingly, chi-square tests for equal proportion and student's t-tests or Wilcoxon Rank Sum test were used to test for differences between groups.

To investigate the change in hospital outcomes over time, logistic and log-linear regression models were used fitting main effects for Status epilepticus, year of admission and patient severity, with patients nested within site and site treated as a random effect. Year of admission was fitted firstly as a categorical variable and then as a continuous variable once linearity was established. Patient severity was calculated as each patient's predicted risk of death in accordance with the Australian and New Zealand Risk of Death (ANZROD) methodology [16]. ANZROD is an updated mortality prediction model specifically

Table 1

Characteristics of patients admitted to ANZ ICUs with primary ICU admission diagnosis of status epilepticus classified according to survival to hospital discharge

\begin{tabular}{|c|c|c|c|}
\hline & All patients & $\begin{array}{l}\text { Survivors } \\
(\mathrm{n}=12,313)\end{array}$ & $\begin{array}{l}\text { Non-survivors } \\
(\mathrm{n}=613)\end{array}$ \\
\hline Age(mean) & $48.7 \pm 18.8$ & $48.03 \pm 18.64$ & $62.7 \pm 16.89$ \\
\hline ICU mortality & $219(2 \%)$ & $0(0 \%)$ & $219(36 \%)$ \\
\hline Hospital mortality & $613(5 \%)$ & $0(0 \%)$ & $613(100 \%)$ \\
\hline \multicolumn{4}{|l|}{ Comorbidities } \\
\hline - Chronic CVS disease & $572(4 \%)$ & $517(4 \%)$ & $55(9 \%)$ \\
\hline - Chronic liver disease & $294(2 \%)$ & $263(2 \%)$ & $31(5 \%)$ \\
\hline - Chronic renal failure & $346(3 \%)$ & $310(3 \%)$ & $36(6 \%)$ \\
\hline - Immune disease & $184(1 \%)$ & $159(1 \%)$ & $25(4 \%)$ \\
\hline - Immunosupression & $293(2 \%)$ & $247(2 \%)$ & $46(8 \%)$ \\
\hline - AIDS & $13(0.1 \%)$ & $9(0 \%)$ & $4(1 \%)$ \\
\hline - Lymphoma & $79(0.6 \%)$ & $67(1 \%)$ & $12(2 \%)$ \\
\hline - Metastases & $235(2 \%)$ & $197(2 \%)$ & $38(6 \%)$ \\
\hline - Leukemia/myeloma & $71(0.5 \%)$ & $57(0 \%)$ & $14(2 \%)$ \\
\hline - Cirrhosis & $279(2 \%)$ & $252(2 \%)$ & $27(4 \%)$ \\
\hline - Insulin Dependent Diabetes & $245(3 \%)$ & $219(3 \%)$ & $26(7 \%)$ \\
\hline - Cancer & $372(3 \%)$ & $312(3 \%)$ & $60(10 \%)$ \\
\hline - Any of above com-morbidities & $1961(15 \%)$ & $1755(14 \%)$ & $206(34 \%)$ \\
\hline Ventilated & $6325(49 \%)$ & $5926(48 \%)$ & $399(66 \%)$ \\
\hline Total Glasgow Coma Score & $10.3 \pm 4.59$ & $10.39 \pm 4.56$ & $7.96 \pm 4.41$ \\
\hline $\begin{array}{l}\text { Acute Renal Failure or (Creatinine }>=300 \text { or Urine output } \\
\text { over } 24 \text { hrs }<500 \text {, without chronic renal impariemnt) }\end{array}$ & $743(6 \%)$ & $662(5 \%)$ & $81(13 \%)$ \\
\hline Any organ failure & $8319(64 \%)$ & $7835(64 \%)$ & $484(79 \%)$ \\
\hline APACHE III risk of death (\%) & $3.2[1-10.2]$ & $2.9[0.9-9.2]$ & $17.3[7-38.3]$ \\
\hline APACHE III score & $47.3 \pm 26.8$ & $45.89 \pm 25.87$ & $76.12 \pm 28.6$ \\
\hline ANZROD (\%) & $1.6[0.7-4.8]$ & $2[1-4]$ & $8[3-19]$ \\
\hline \multicolumn{4}{|l|}{ Admission source } \\
\hline - ICU admission from ED & $9370(73 \%)$ & $9065(74 \%)$ & $305(50 \%)$ \\
\hline - ICU admission from Ward & $3534(27 \%)$ & $3226(26 \%)$ & $308(50 \%)$ \\
\hline
\end{tabular}

NB. All comparisons between survivors and non-survivors were significant with p value $<.0001$.

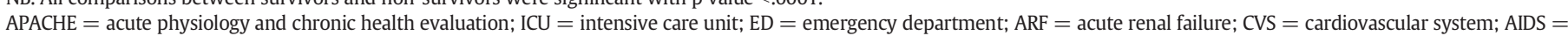
acquired immunodeficiency syndrome; ANZROD = Australian and New Zealand Risk of Death. 
Table 2

Secondary outcomes for survivors and non-survivors

\begin{tabular}{llll}
\hline & All patients & Survivors & Non-survivors \\
\hline Hospital Type: Rural & $2805(22 \%)$ & $2721(22 \%)$ & $84(14 \%)$ \\
$\begin{array}{l}\text { Hospital Type: Tertiary } \\
\text { Hospital Outcome }\end{array}$ & $5903(46 \%)$ & $5558(45 \%)$ & $345(56 \%)$ \\
$\quad$ - Death & $613(5 \%)$ & $0(0 \%)$ & $613(100 \%)$ \\
- Rehab & $813(6 \%)$ & $813(7 \%)$ & $0(0 \%)$ \\
- Other hospital & $941(7 \%)$ & $941(8 \%)$ & $0(0 \%)$ \\
Length of Stay & & & \\
$\quad$ - Hours in hospital prior & $4.95[2.2-16.1]$ & $4.83[2.2-14.3]$ & $14.43[3.6-117.4]$ \\
$\quad$ to ICU admission & & & \\
- ICU LOS (hours) & $38.5[21-68.6]$ & $37.7[20.5-66.2]$ & $83.3[35.6-183.8]$ \\
- Hospital LOS (days) & $6.28[3-13.7]$ & $6.02[2.9-12.9]$ & $13.95[6.8-29]$ \\
\hline
\end{tabular}

NB. All comparisons between survivors and non-survivors were significant with p value $<.0001$.

ICU = intensive care unit; LOS = length of stay.

calibrated for use in Australian and New Zealand ICUs. It has been derived from components of the APACHE II and III scoring systems with additional diagnostic variables and combines eight risk adjustment algorithms, one for each major diagnostic group. It has been shown to have significantly better calibration and discrimination than APACHE III [16]. Results from logistic regression are reported as Odds Ratios (median with IQR), whilst analysis of log-transformed length of stays are reported as geometric means $(95 \% \mathrm{CI})$. To determine if the relationship between outcome and year of admission was significantly affected by ventilation status, an interaction between ventilation and year was fitted to the models. Changes in incidence over time were determined using Pearson or Spearman correlation coefficients.

To ensure consistency of results across a stable population, sensitivity analysis was performed by repeating all analysis on a subpopulation of 59 hospitals that provided data for each of the 14 years of the study period. Statistical analysis was performed using SAS version 9.4 (SAS Institute Inc., Cary, NC, USA). A two sided p-value of 0.05 was considered to be statistically significant.

\section{Results}

Overall, 1,250,449 patients were admitted to 199 ICUs (out of a total of 200 bi-nationally) which contribute to the bi-national Australia and New Zealand Intensive Care Society (ANZICS) database from 2000-2013. Of these patients, 12,926 (1.1\%) were admitted to ICUs with the primary admission diagnosis of Status epilepticus (SE). Their characteristics are shown in Table 1. (See Table 2.)

The change in the proportion of SE admissions in relation to all ICU admissions over time showing an increase from $0.93 \%$ in 2000 to $1.13 \%$ in $2013(P=.02)$. Similarly, the estimated population incidence of SE increased from 30 to 61 per million population in Australia and New Zealand in 2013.

\subsection{Outcomes}

During the 14-year study period, 219 (1.7\%) Status epilepticus (SE) patients died in ICU and 613 (4.7\%) died in hospital (Table 1). The 613 patients who died in hospital had more co-morbidities and were older; their APACHE III score was higher, as was their admission
Table 4

Parameter estimates (standard errors) for the annual change in log (length of stay) for survivors and non-survivors stratified by country with the p-value indicating that there was no evidence to suggest that the annual changes in log (length of stay) differed according to country

\begin{tabular}{llll}
\hline Outcome & Australia & New Zealand & Interaction P-value \\
\hline Hospital Length of Stay & & \\
Survivors & $-0.013(0.003)$ & $-0.013(0.011)$ & 0.68 \\
Non-Survivors & $0.022(0.013)$ & $-0.102(0.050)$ & 0.10 \\
ICU Length of Stay & & & \\
Survivors & $0.011(0.002)$ & $0.017(0.008)$ & 0.09 \\
Non-Survivors & $0.051(0.023)$ & $-0.087(0.147)$ & 0.06 \\
\hline
\end{tabular}

estimated probability of death. They also had a lower Glasgow Coma Scale (GCS) score on admission, higher rates of mechanical ventilation, higher rates of organ failures, particularly acute renal failure and were more likely to be admitted to ICU from the ward.

Overall mortality decreased from $8.2 \%$ in 2000 to $4 \%$ in 2013 . Similarly, ICU mortality decreased from $2.6 \%$ in 2000 to $0.75 \%$ in 2013 (Fig. 1).

Survivors were discharged home in most cases [10,559 (81.7\%)] (Fig. 2), while others were discharged to another hospital [941 (7.3\%)] (Fig. 3) or to a rehabilitation facility [813 (6.3\%] with a significant increase in patients in such rehabilitation admissions (Fig. 4). Nonsurvivors had a longer stay in ICU at $83 \mathrm{hrs}$ [95\% CI 36-184] compared to survivors at 38 hours [21-66]. They also had a longer overall hospital stay 13.9 [95\% CI 6.8-29] days compared with survivors 6 days [2.9-13]. Overall ICU length of stay increased over time from 1.45 days in 2000 to 1.77 days in $2013(\mathrm{P}=.004)$. In contrast, hospital length of stay (LOS) decreased significantly during the study period from 6.64 days in 2000 to 5.81 days in $2013(\mathrm{P}<.0001)$ (Fig. 5).

There was no significant difference between Australia and New Zealand in outcomes (Table 3). Similarly there was no difference between the two countries in both hospital and ICU length of stay (Table 4).

\subsection{Patients treated with mechanical ventilation}

Overall 6325 (49\%) patients received mechanical ventilation within the first 24 hours of ICU admission. Ventilated patients were more acutely ill and thus had a lower Glasgow Coma Scale (GCS), higher APACHE III scores, lower systolic blood pressure, and a higher rate of acute renal failure (Table 5). The proportion of mechanically ventilated patients decreased from $56.6 \%$ in 2000 to $47.2 \%$ in 2013 ( $\mathrm{P}=.0015$ ).

Overall 399 (6\%) of mechanically ventilated patients died and of these, $170(42.6 \%)$ died in the ICU. In contrast among non ventilated patients only 210 (3\%) died in hospital and of these only 48 died in ICU (1\%). Ventilated patients had a longer length of stay both in the ICU and in the hospital (Table 6). Among ventilated patients, overall mortality changed from $9.8 \%$ in 2000 down to $4.9 \%$ in 2013 ( $\mathrm{P}=.0003)$. Non-ventilated patients had a change in mortality from $6.0 \%$ in 2000 to $3.3 \%$ in 2013 ( $\mathrm{P}=$ .0006). There was no significant difference in the adjusted annual rate of decline in mortality between ventilated and non-ventilated patients [OR 0.94 (0.91-0.97) vs OR (0.93 (0.89-0.97) P = .95].

Similarly, ICU mortality decreased from $2.6 \%$ in 2000 to $1.0 \%$ in 2013 in ventilated patients, while in non-ventilated patients, it decreased from $2.7 \%$ in 2000 down to $0.6 \%$ in 2013 [(OR $0.94(0.90-0.99)$ vs OR $0.93(0.85-1.01) \mathrm{P}=.88]$.

Table 3

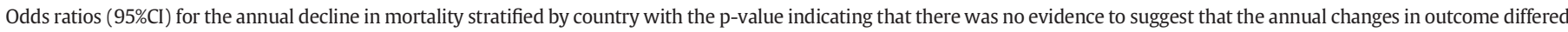
according to country

\begin{tabular}{|c|c|c|c|}
\hline Outcome & Australia & New Zealand & Interaction P-value \\
\hline Hospital mortality & $0.930(0.908-0.953)$ & $0.861(0.765-0.969)$ & 0.21 \\
\hline Discharge Home & $0.998(0.985-1.012)$ & $1.007(0.946-1.073)$ & 0.83 \\
\hline Discharge Other Hospital & $1.007(0.988-1.027)$ & $1.085(0.980-1.201)$ & 0.15 \\
\hline Rehabilition & $1.058(1.034-1.083)$ & $1.006(0.909-1.112)$ & 0.34 \\
\hline
\end{tabular}


Table 5

Baseline characteristics of study patients according to the use of mechanical ventilation

\begin{tabular}{|c|c|c|c|}
\hline & All patients & $\begin{array}{l}\text { Not Ventilated } \\
(\mathrm{n}=6601)\end{array}$ & $\begin{array}{l}\text { Ventilated } \\
(\mathrm{n}=6325)\end{array}$ \\
\hline Age(mean) & $47.4[33.2-63.5]$ & $46.2[32-62.7]$ & $48.7[34.8-64.3]$ \\
\hline Male Gender & $7386(57 \%)$ & $3416(52 \%)$ & $3970(63 \%)$ \\
\hline Ventilated & $6325(49 \%)$ & $0(0 \%)$ & $6325(100 \%)$ \\
\hline ICU mortality & $218(2 \%)$ & $48(1 \%)$ & $170(3 \%)$ \\
\hline Hospital mortality & $609(5 \%)$ & $210(3 \%)$ & $399(6 \%)$ \\
\hline Total Glasgow Coma Score & $10.3 \pm 4.59$ & $12.01 \pm 3.8$ & $8.54 \pm 4.65$ \\
\hline \multicolumn{4}{|l|}{ Comorbidities } \\
\hline - Chronic CVS disease & $572(4 \%)$ & $344(5 \%)$ & $228(4 \%)$ \\
\hline Respiratory Arrest & $161(2 \%)$ & $57(1 \%)$ & $104(2 \%)$ \\
\hline Acute Renal Failure & $303(2 \%)$ & $104(2 \%)$ & $199(3 \%)$ \\
\hline Any organ failure & $8318(64 \%)$ & $1993(30 \%)$ & $6325(100 \%)$ \\
\hline Apache III risk of death (\%) & $3.2[1-10.2]$ & $1.6[0.6-4.9]$ & $6.4[2.1-16.2]$ \\
\hline APACHE III score & $47.3 \pm 26.8$ & $37 \pm 22.3$ & $58 \pm 26.8$ \\
\hline $\mathrm{MAP}<65$ or $\mathrm{SBP}<90$ & $3416(27 \%)$ & $1525(23 \%)$ & $1891(30 \%)$ \\
\hline Elective surgery & $904(7 \%)$ & $699(11 \%)$ & $205(3 \%)$ \\
\hline \multicolumn{4}{|l|}{ Admission source } \\
\hline - Hosp. admission from home & $10,206(79 \%)$ & $5427(82 \%)$ & $4779(76 \%)$ \\
\hline - ICU admission from ED & $9354(73 \%)$ & $4229(64 \%)$ & $5125(81 \%)$ \\
\hline - ICU admission from Ward & $3531(27 \%)$ & $2334(35 \%)$ & $1197(19 \%)$ \\
\hline \multicolumn{4}{|l|}{ Hospital type } \\
\hline - Rural hospital & $2805(22 \%)$ & $2005(30 \%)$ & $800(13 \%)$ \\
\hline - Metropolitan hospital & $3453(27 \%)$ & $1885(29 \%)$ & $1568(25 \%)$ \\
\hline - Tertiary hospital & $5884(46 \%)$ & $2058(31 \%)$ & $3826(60 \%)$ \\
\hline - Private hospital & $765(6 \%)$ & $634(10 \%)$ & $131(2 \%)$ \\
\hline
\end{tabular}

NB. All comparisons between survivors and non-survivors were significant with p value $<.0001$.

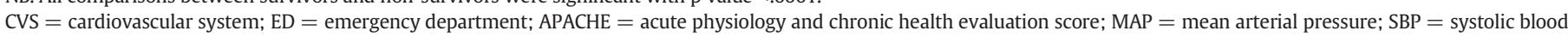
pressure.

\section{Discussion}

\subsection{Key findings}

We used the ANZICS Adult Patient Database to study the ICU incidence, population incidence, features, aspects of ICU treatment and outcomes of patients admitted to ICU with the primary diagnosis of Status epilepticus (SE) over a fourteen year period. We found that the ICU prevalence of such SE increased significantly over time by $20 \%$. In contrast its yearly population incidence increased more than two-fold. Moreover, we found that the percentage of patients receiving mechanical ventilation decreased by almost $10 \%$ and hospital length of stay also decreased, while ICU length of stay increased. In addition, overall mortality was low; was associated with multiple markers of illness severity, and halved by 2013. Finally, although four fifths of patients were discharged home, the percentage of patients discharged to rehabilitation facilities increased threefold over the study period.

\subsection{Relationship with previous studies}

To our knowledge, no previous studies have assessed the incidence and outcome of patients admitted to ICU because of the primary diagnosis of Status epilepticus (SE). In contrast, previous ICU based studies $[2-4,6,8-10,17-20]$ of SE have included patients with the ICU admission diagnosis of brain pathology (Traumatic brain injury, brain tumor, encephalitis, stroke) who developed SE subsequently as a secondary event. As far as we know, this is also by far the largest cohort of ICU patients with SE. It is also the only to assess the epidemiology of SE at a binational level, in the setting of the ICU and in patients requiring mechanical ventilation.

The incidence of SE as the reason for admission to ICU has not been previously defined. However, among the elderly, SE has previously been reported at 86 per 100,000 per year in the USA [21]. In Germany the overall yearly incidence of SE was reported at 54.5 per 100,000 in patients over 60 years of age [22]. In terms of population incidence, SE has been previously reported in Switzerland at 10.3 per 100,000 and in Europe as $15-20$ per 100,000 per year [6,8]. The systematic review by Chin et al. [23] reported an incidence rate between 9.9 and 41 per 100,000 per year. In our study we report for the first time that the incidence of ICU admissions specifically due to SE in Australia and New Zealand was approximately 60 per million per year with a two-fold increase in incidence from 2000-2013. A similar increase in incidence over time has been noted in other studies [24].

The mortality of SE (primary and secondary) treated in hospital (but not necessarily in ICU) has been previously reported to vary from $3.45 \%$ [1] and 67\% [10]. In 2013, a consensus statement from a status epilepticus conference reported mortality at 20\% [11]. In contrast, the overall hospital mortality in this study over 14 years was $4.7 \%$, a value in the

Table 6

Outcomes of ventilated compared with non-ventilated patients

\begin{tabular}{|c|c|c|c|}
\hline & All patients & Not Ventilated & Ventilated \\
\hline \multicolumn{4}{|l|}{ Hospital Outcome } \\
\hline - Death & $609(5 \%)$ & $210(3 \%)$ & $399(6 \%)$ \\
\hline - Home & $10,546(82 \%)$ & $5527(84 \%)$ & $5019(79 \%)$ \\
\hline \multicolumn{4}{|l|}{ Length of Stay } \\
\hline - Hospital LOS prior to ICU admission (hours) & $5[2.2-16.1]$ & $7[3.1-24.6]$ & $4[1.6-8.3]$ \\
\hline - ICU LOS (hrs) & $38[20.8-68.6]$ & $29[17.8-51.4]$ & $46[26.3-88.6]$ \\
\hline - Hospital LOS for survivors (days) & $6[2.92-12.9]$ & $5.3[2.5-11.4]$ & $6.8[3.6-14.2]$ \\
\hline - ICU LOS for survivors (days) & $1.6[0.9-2.8]$ & $1.2[0.7-2.1]$ & $1.9[1.1-3.6]$ \\
\hline
\end{tabular}

NB. All comparisons between survivors and non-survivors were significant with $\mathrm{p}$ value $<.0001$.

$\mathrm{ICU}=$ intensive care unit; LOS = length of stay. 


\section{Raw mortality}

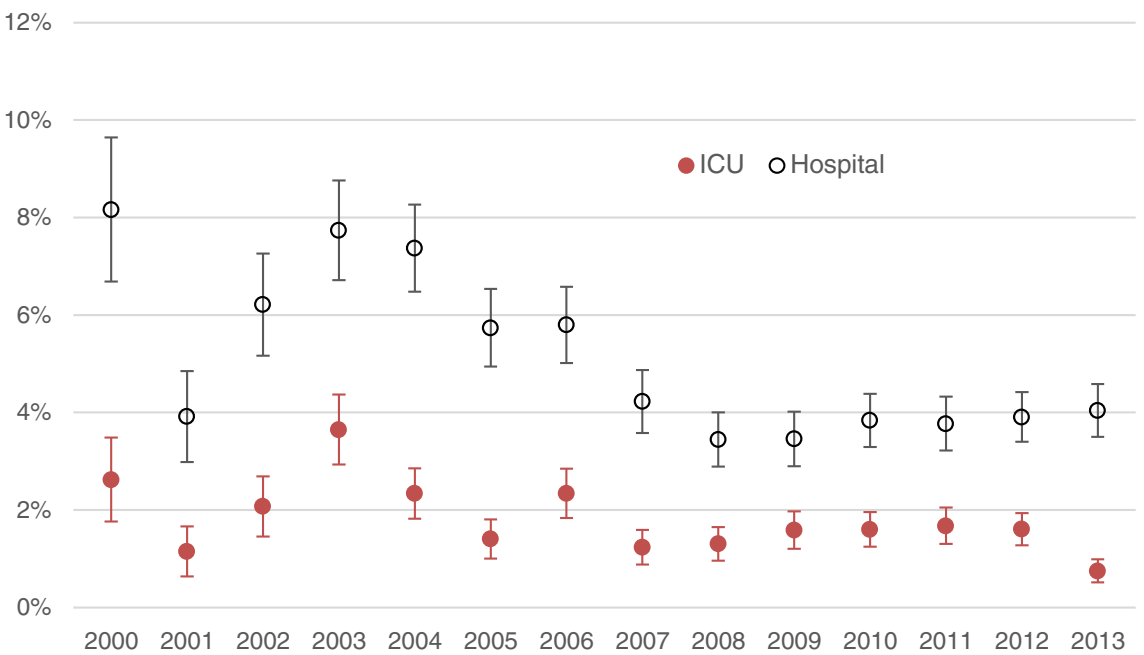

Fig. 1. Changes in both hospital and ICU mortality over time.

lower range of previous studies. Among studies performed in ICU patients, the ICU mortality also varied from $11 \%$ [2] to $67 \%$ [10]. Our ICU mortality was therefore markedly lower than in such studies. This may be due to these patients having primary SE. Previous studies suggested that the mortality of patients with SE is dependent upon the underlying trigger with severe organic brain disease patients having a worse outcome $[1,9]$. However, no studies to date have specifically selected out those patients admitted to ICU with the primary ICU admission diagnosis of SE. Thus, we cannot directly compare our findings with those of any previous study. Nonetheless our ICU mortality in 2013 is the lowest reported for any SE population so far at $0.75 \%$.

Mechanical ventilation has been associated with a threefold increased risk [1] in mortality. Correspondingly respiratory failure [1] and longer duration of ventilation [5] have also been associated with increased risk of death. In our cohort, we demonstrated a two-fold increased risk of hospital and ICU mortality in patients receiving mechanical ventilation. However, even in ventilated patients overall mortality was low.

Only $49 \%$ of patients in our dataset received mechanical ventilation in the first 24 hours. This may be due to awareness of the increased mortality associated with ventilation. Other factors that may have contributed included patients being observed in ICU as a precautionary measure such that if there was further deterioration and loss of ability to maintain the airway, they could be intubated in a safe, nonemergent environment. We assume that patients who did not receive mechanical ventilation would have been able to recover from their recurrent seizures enough to be able to maintain a patent airway and thus not require mechanical ventilation.

A lower mean Glasgow Coma Scale (GCS) score on admission to ICU was associated with mortality in our study. Stuporous and comatose states at onset of status SE in other papers are reported to have increased mortality rates $[3,9,25]$. Correspondingly longer duration of SE $[2,9]$ and continuous seizure activity $[2,3]$ have also been associated with increased mortality.

The median ICU length of stay for non-survivors in our dataset was approximately 3.5 days. The use of mechanical ventilation was associated with a further increase in length of stay to approximately six days. This is similar to other studies which demonstrated a median overall ICU stay of close to five days [2,3]. In our cohort, non-survivors had an overall median longer hospital length of stay of approximately two weeks, a finding similar to previous studies $[2,8,26]$.

\section{DischargeRehab}

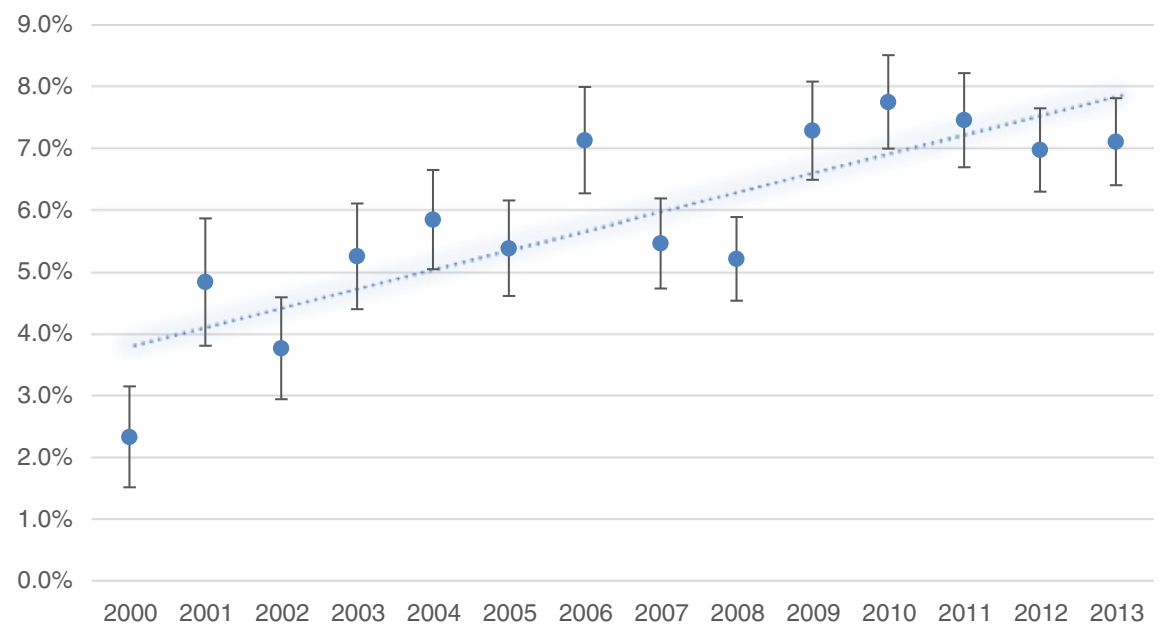

Fig. 2. The percentage of patients discharged to Rehabilitation facilities over time. 
Discharge Home

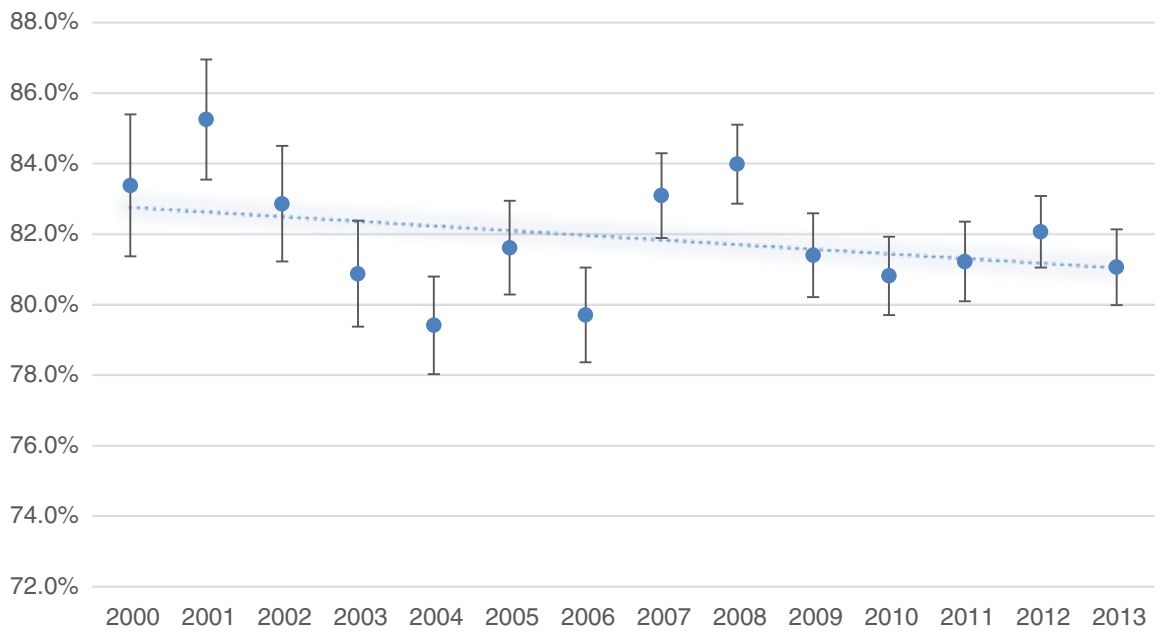

Fig. 3. Percentage of patients discharged home by year.

Our outcomes beyond mortality were also better than those documented in other studies $[1,8,9]$. Investigators in the USA documented $76.4 \%$ of patients returning home versus $81.7 \%$ in our study and $20 \%$ discharged to rehab versus $6.3 \%$ in our study.

\subsection{Implications of study findings}

Our study demonstrates that in ANZ ICUs, among patients with SE as the primary ICU admission diagnosis, the prevalence, population incidence, and length of ICU stay have increased over fourteen years. However, at the same time, the use of mechanical ventilation, raw and adjusted ICU mortality, and hospital mortality have all significantly decreased. These observations imply that the management of SE has changed over time with decreased use of ventilation, suggesting either ICU admission of less acutely ill patients or use of treatments that do not require deep sedation or both. The fact that improved outcomes remained significant despite adjustment for illness severity suggests that real improvements in management may have taken place.

Moreover, the above changes in outcomes occurred independently of mechanical ventilation and were associated with a three-fold increase in the proportion of patients discharged to a rehabilitation facility. These observations imply that, although performance has improved in terms of survival, as older patients are treated the need for prolonged recovery becomes more important. Finally, these findings provide a useful benchmark against which, other as well as our own, health care systems can compare themselves and a useful set of values for future quality assessment and interventional studies.

\subsection{Strengths and weaknesses of study}

Our study has several strengths. The ANZICS ICU database provided a large cohort of patients and a large pool of data from close to $90 \%$ of ICUs in Australia and New Zealand. This makes it readily applicable and representative of a wide range of ICU patients. This dataset represents by far the largest cohort of ICU patients with the admission diagnosis of SE. In these patients, we had information on physiological characteristics on the day of admission, as well as information on duration of stay, need for mechanical ventilation, mortality and discharge destination. Indirect information on their functional outcome upon discharge was represented by their discharge destination. Such detailed information provides an understanding of the characteristics of such patients and an appreciation of their outcomes and the change in such outcomes over more than a decade.

\section{DischargeOtherHosp}

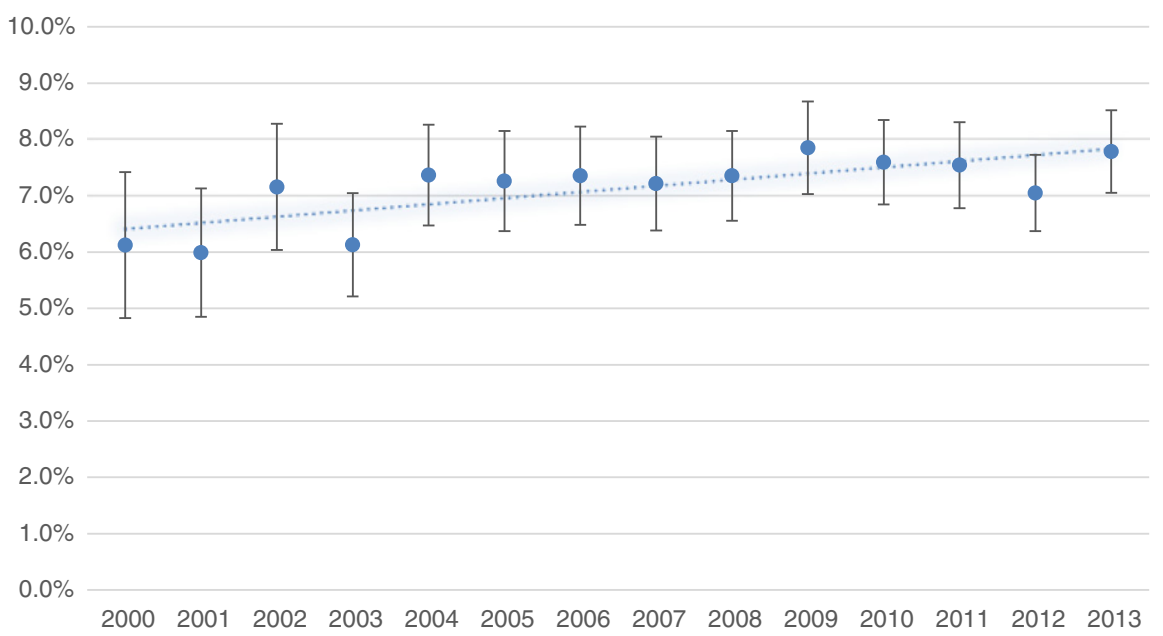

Fig. 4. Percentage of patients discharged to other hospitals. 


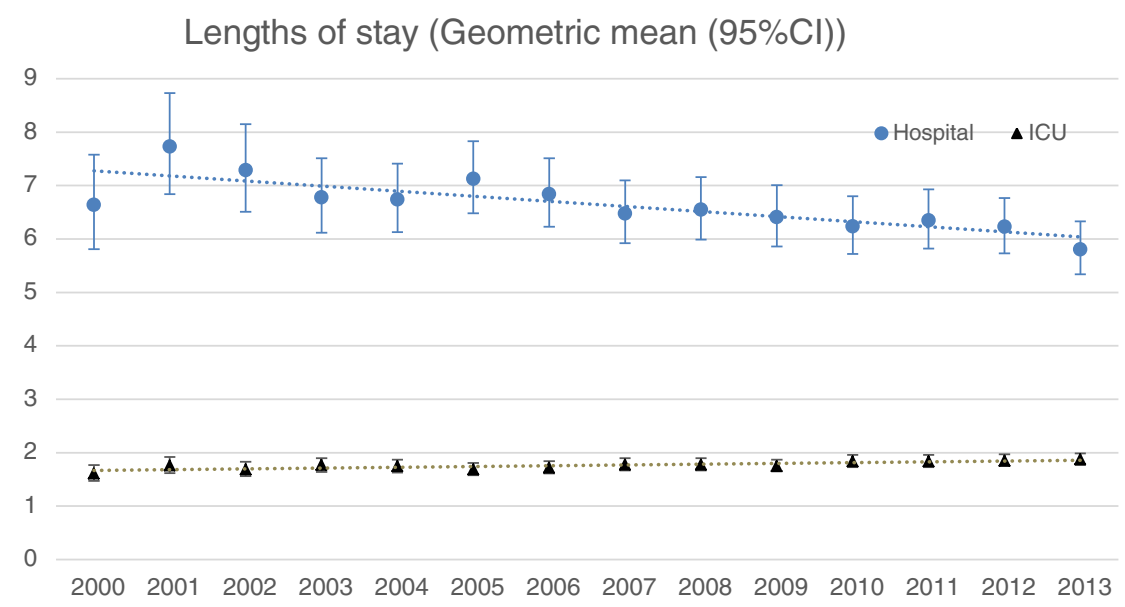

Fig. 5. Length of stay per year.

However, this study also carries several limitations. First, it is an observational, retrospective study, which relies on the data being entered appropriately and completely. However, the Australian and New Zealand Intensive Care Society (ANZICS) Adult Patient Database data has been previously shown to have a high level of accuracy, making it likely that the data are accurate and unbiased [13]. The definition of SE has changed over recent years and that may have affected the total numbers in this dataset. However, as the clinical characteristics of such patients are typically manifest and obvious to any clinician and as these patients were admitted to ICU with this SE as the primary diagnosis for admission, it is unlikely that changes in diagnostic assessment would account for our findings.

These patients with a primary diagnosis of SE have not been identified and studied in previous investigations. As such they represent a unique cohort of patients. The etiology of SE in these patients is not documented. However, the diagnostic code used for primary seizures in the ANZICS database specifically excludes seizures in patients primarily admitted to ICU because of structural brain disease. Thus, the incidence reported here may under-estimate the total number of admissions who experienced SE in ICU.

The underlying etiology of these patients likely includes patients with prior epilepsy, non-compliance with anti-epileptics, lower seizure threshold and metabolic disturbances among other causes. These factors may be associated with a better prognosis than those with underlying structural brain disease and secondary SE. This makes a comparison with previous studies, including a broader range of SE patients and SE patients with structural brain disease, more difficult. Our low mortality rates may then be difficult to compare directly with other studies as they may be due to the underlying causality.

Our dataset carries no information on interventions, treatment and management, except for the use of mechanical ventilation, making it difficult to assess how the management of these patients has changed overtime and whether changes in management over time may account for the improved outcomes. In the epilepsy community there is still no defined optimal treatment of refractory and super-refractory status epilepticus and no commonly accepted treatment protocol exists [11]. The database only provides information about whether mechanical ventilation occurred in the first 24 hours of admission, thus patients who required ventilation later during their ICU stay were not documented. However, the change in the use of mechanical ventilation implies either a change in admission criteria or the less frequent use of intensive sedation or drug induced coma or both.

The overall hospital and ICU mortality over the fourteen year period in this study decreased. However, there was a marked decrease in overall mortality in 2001 and 2002 which we have no clear explanation for.
As this is an ICU database it may also have missed those patients who died prior to medical presentation or prior to ICU admission. This seems unlikely as SE is typically not a cause of immediate death per se.

\section{Conclusions}

In Australia and New Zealand ICUs, the prevalence and population incidence and the length of ICU stay of patients with SE as the primary ICU admission diagnosis have increased over the last decade and a half, while mechanical ventilation use, hospital length of stay, ICU and hospital mortality have significantly decreased. In particular mortality in these patients is now $<1 \%$. This decrease in mortality, however, has been associated with a three-fold increase in the proportion of patients discharged to a rehabilitation facility. These findings provide a useful benchmark for other health care systems and for future quality improvement and interventional studies.

\section{Disclosure of Conflicts of Interest}

None of the authors has any conflict of interest to disclose.

\section{Ethical Publication Statement}

We confirm that we have read the Journal's position on issues involved in ethical publication and affirm that this report is consistent with those guidelines.

\section{Acknowledgments}

We would like to thank ANZICS for access to the database for the purposes of this study.

\section{Appendix A. Supplementary data}

Supplementary data to this article can be found online at http://dx. doi.org/10.1016/j.jcrc.2016.03.003.

\section{References}

[1] Koubeissi M, Alshekhlee A. In-hospital mortality of generalized convulsive status epilepticus: a large US sample. Neurology 2007;69(9):886-93.

[2] Legriel S, Azoulay E, Resche-Rigon M, Lemiale V, Mourvillier B, Kouatchet A, et al. Functional outcome after convulsive status epilepticus. Crit Care Med 2010; 38(12):2295-303

[3] Legriel S, Mourvillier B, Bele N, Amaro J, Fouet P, Manet P, et al. Outcomes in 140 critically ill patients with status epilepticus. Intensive Care Med 2008;34(3):476-80. 
[4] Holtkamp M, Othman J, Buchheim K, Meierkord H. Predictors and prognosis off refractory status epilepticus treated in a neurological intensive care unit. J Neurol Neurosurg Psychiatry 2005;76(4):534-9.

[5] Kowalski RG, Ziai WC, Rees RN, Werner Jr JK, Kim G, Goodwin H, et al. Third-line antiepileptic therapy and outcome in status epilepticus: the impact of vasopressor use and prolonged mechanical ventilation. Crit Care Med 2012;40(9):2677-84

[6] Sutter R, Tschudin-Sutter S, Grize L, Fuhr P, Bonten MJM, Widmer AF, et al. Associations between infections and clinical outcome parameters in status epilepticus: a retrospective 5-year cohort study. Epilepsia 2012;53(9):1489-97.

[7] Rossetti AO, Bleck T. What's new in status epilepticus? Intensive Care Med 2014;40: 1359-62.

[8] Rudin D, Grize L, Schindler C, Marsch S, Rüegg S, Sutter R. High prevalence of nonconvulsive and subtle status epilepticus in an ICU of a tertiary care center: A three year observational study. Epilepsy Res 2011;96:140-50.

[9] Sutter R, Marsch S, Fuhr P, Rüegg S. Mortality and recovery from refractory status epilepticus in the intensive care unit: A 7-year observational study. Epilepsia 2013; 54(3):502-11.

[10] Drislane F, Lopez M, Blum A, Schomer D. Detection and Treatment of Refractory Status Epilepticus in the Intensive Care Unit. J Clin Neurophysiol 2008;25(4): 181-6.

[11] Trinka E, Shorvon S. Status epilepticus- Where are we in 2013? Epilepsia 2013; 54(Suppl. 6):1-2.

[12] Shorvon S, Trinka E. 5th London-Innsbruck Colloquium on Status Epilepticus and Acute Seizures. Epilepsy Behav 2015;49:1-3.

[13] Stow PJ, Hart GK, Higlett T, George C, Herkes R, McWilliam D, et al. ANZICS Database Management Committee. Development and implementation of a high-quality clinical database: the Australian and New Zealand Intensive Care Society Adult Patient Database. J Crit Care 2006;21(2):133-41.

[14] Australian Bureau of Statistics. http://www.abs.gov.au/AUSSTATS/abs@.nsf/ DetailsPage/3101.0Dec 2012?OpenDocument. [Accessed August 1, 2013].
[15] QuickStats About New Zealand's Population and Dwellings. Statistics New Zealand. http://www.stats.govt.nz/Census /2006CensusHomePage/QuickStats/quickstatsabout-a-subject/nzs-population-and-dwellings.aspx. [Accessed August 1, 2013].

[16] Paul E, Bailey M, Pilcher D. Risk prediction of hospital mortality for adult patients admitted to Australian and New Zealand intensive care units: development and validation of the Australian and New Zealand Risk of Death model. J Crit Care 2013;28(6):935-41.

[17] Schmutzhard E, Pfausler B. Complications of the management of status epilepticus in the intensive care unit. Epilepsia 2011;52(Suppl. 8):39-41.

[18] Goulon M, Levy-Alcover MA, Nouailhat F. Status epilepticus in the adult. Epidemiologic and clinical study in the intensive care unit. Rev Electroencephalogr Neurophysiol Clin 1985;14(4):277-85.

[19] Sagduyu A, Tarlaci S, Sirin H. Generalized tonic-clonic status epilepticus: causes, treatment, complications and predictors of case fatality. J Neurol 1998;245:640-6.

[20] Hocker S, Britton J, Mandrekar J, Wijdicks E, Rabinstein A. Predictors of Outcome in Refractory Status Epilepticus. JAMA Neurol 2013;70(1):72-7.

[21] DeLorenzo RJ, Hauser WA, Towne AR, Boggs JG, Pellock JM, Penberthy L, et al. A prospective, population-based epidemiologic study of status epilepticus in Richmond, Virginia. Neurology 1996;46(4):1029-35.

[22] Knake S, Rosenow F, Vescovi M, Oertel WH, Mueller H, Wirbatz A, et al. Incidence of Status Epilepticus in Adults in Germany: A Prospective, Population Based-Study. Epilepsia 2001;42(6):714-8.

[23] Chin RFM, Neville BGR, Scott RC. A systematic review of the epidemiology of status epilepticus. Eur J Neurol 2004;11:800-10.

[24] Logroscino G, Hesdorffer DC, Cascino G, Annegers JF, Hauser WA. Time Trends in Incidence, Mortality, and Case-Fatality after First Episode of Status Epilepticus. Epilepsia 2001;42(8):1031-5.

[25] Marchi N, Novy J, Faouzi M, Stähli C, Burnand B, Rossetti AO. Status Epilepticus: Impact of Therapeutic Coma on Outcome. Crit Care Med 2015;43:1003-9.

[26] Coeytaux A, Jallon P, Galobardes B, Morabia A. Incidence of status epilepticus in French-speaking Switzerland (EPISTAR). Neurology 2000;55:693-7. 